\title{
Sex differences in infant habituation research: A survey and some hypotheses
}

\author{
THOMAS J. TIGHE and LISA BEALE POWLISON \\ Dartmouth College, Hanover, New Hampshire 03755
}

The literature on infant habituation was reviewed for evidence of sex differences in performance. While a majority of the studies do not report analyses for sex differences, studies finding such differences still constitute a significant proportion of the literature. Twenty-two procedural variables were examined in relation to the varying outcomes of the studies. The findings suggest that sex differences in habituation performance are related to the distribution of habituation training and implicate faster stimulus processing by male infants and/or more complete or detailed processing by females.

An intriguing, but puzzling, aspect of the burgeoning infant habituation literature concerns sex differences in performance. The literature in this area conveys the general impression that sex differences in infant habituation are both prevalent and confusing in nature (Coken \& Gelber, 1975; Maccoby \& Jacklin, 1974). However, the generality of sex differences in the literature has not been comprehensively examined, nor has there been any effort to review procedural variables in relation to the presence vs. absence or direction of sex differences in performance.

The review presented here was restricted to studies employing subjects less than 1 year of age and includes studies published between 1952 and mid-1977. Only studies obtaining habituation were included, that is, only research which observed response decrement to a repeatedly presented stimulus followed by response recovery upon the introduction of a novel stimulus.

\section{INCIDENCE OF SEX DIFFERENCE FINDINGS}

Seventy-two studies fell within the limits of the review as defined above. The data from $38(53 \%)$ of the studies could not be brought to bear on the question of sex differences. Two of the 38 investigations used only female infants (Melson \& McCall, 1970; Moreau, Birch, \& Turkewitz, 1970), and 5 employed male infants solely (Horowitz, 1972; McCall \& Melson, 1969, 1970; Miller, 1972; Miller, Turnure, \& Cohen, 1970). The remainder of the studies in this group reported no analyses with respect to sex (Allen, Walker, Symonds, \& Marcell, 1977; Appel \& Campos, 1977; Bartoshuk, 1962a; Bridger, 1961; Bronshtein \& Petrova, 1952; Clifton, Graham, \& Hatton, 1968; Collard \& Rydberg, 1972; Dirks \& Gibson, 1977; Eisenberg, Coursin, \& Rupp, 1966; Engen \& Lipsitt, 1965; Engen, Lipsitt, \& Kaye, 1963; Fantz, 1964; Friedman, Carpenter, \& Nagy, 1970; Friedman, Schlossnagle, Ramsey, \& Rogers, 1973; Graham, Clifton, \& Hatton, 1968; Hutt, von Bernuth, Lenard, Hutt, \& Prechtl, 1968; Keen, Chase, \& Graham, 1965; Leavitt, Brown, Morse, \& Graham, 1976; McGurk, 1970, 1972; Miller, Ryan, Sinnott, \& Wilson, 1976; Morse, 1972; Ruff, 1975; Saayman, Ames, \& Moffett, 1964; Schaffer \& Parry, 1969; Schaffer, Greenwood, \& Parry, 1972; Ames, Note 1; Cohen, Note 2, Note 3; Hunter \& Ames, Note 4; Miller, Adams, \& Ryan, Note 5).

Thirty-four of the 72 studies reviewed produced data pertinent to the issue of sex differences. Of these, seven $(21 \%)$ found sex differences in habituation: Four investigations showed that rate of habituation and/or degree of discriminative response recovery were greater for male infants (Cohen, DeLoache, \& Rissman, 1975; Cohen, Gelber, \& Lazar, 1971; Cornell \& Strauss, 1973; Pancratz \& Cohen, 1970), while three demonstrated superior female performance (Caron \& Caron, 1969; Friedman, Bruno, \& Vietze, 1974; Meyers \& Cantor, 1966).

The locus of performance difference varied in the seven studies showing sex differences. Caron and Caron (1969) found that, although both male and female infants' visual fixations decreased and showed recovery to a new stimulus, the females displayed a faster rate of habituation. Friedman et al. (1974) demonstrated decremented visual fixation and subsequent recov-

Send reprint requests to T. J. Tighe, Department of Psychology, Dartmouth College, Hanover, New Hampshire 03755 ery of fixation to a highly discrepant stimulus for both sexes, but found that only the female newborns showed response recovery to a moderately discrepant stimulus. Monitoring cardiac responses, Meyers and Cantor (1966) found that female infants' heart rate decelerations decreased with repeated stimulus presentations, evidencing reduced attention, while the males' decelerations increased in frequency over the course of the experiment. With regard to sex differences in the opposite direction, Cohen et al. $(1975,1971)$ and Pancratz and Cohen (1970) found that males', but not females', visual fixations habituated with repeated viewing of a stimulus. In Cornell and Strauss (1973), only male infants showed reliable decreases in fixation time over trials.

The remainder of the studies reporting analyses for sex differences in performance showed no significant differences on any measure of habituation (Adkinson \& Berg, 1976; Bartoshuk, 1962b; Berg, 1972, 1974; Bornstein, 1976; Brown, 1974; Caron \& Caron, 1968; Caron, Caron, Caldwell, \& Weiss, 1973; Cohen, DeLoache, \& Pearl, 1977; DeLoache, 1976; Friedman, 1972; Friedman \& Carpenter, 1971; Friedman, Nagy, \& Carpenter, 1970; Greenberg, O'Donnell, \& Crawford, 1973; Johnson \& Brody, 1977; Kagan \& Lewis, 1965; Keen, 1964; Martin, 1975; McCall, 1973; McCall, Hogarty, Hamilton, \& Vincent, 1973; McCall \& Kagan, 1970; McCall, Kennedy, \& Dodds, 1977; Parry, 1972; Steele \& Pederson, 1977; Wetherford \& Cohen, 1973; Young-Browne, Rosenfeld, \& Horowitz, 1977; Miller, Deslauriers, \& Farrow, Note 6). ${ }^{1}$

Using the conventional alpha level of .05 as a reference, the number of studies obtaining sex differences constitutes a small but statistically significant proportion (10\%) of the total literature on infant habituation. It should be emphasized that this statistical evaluation includes the 38 studies that could not be brought to bear on the issue. Hence, the $10 \%$ figure is a conservative estimate of the rate of sex difference findings.

The large class of "fail to report" studies (approximately half of the literature) in relation to the incidence of sex difference findings in the balance of the literature clearly indicates the need for greater consideration of sex differences by investigators in the area.

\section{EXAMINATION OF PROCEDURAL VARIABLES}

Can the presence and directionality of the observed sex differences be related to particular experimental conditions? To deal with this question, the literature was considered with respect to a wide variety of procedural details that might reasonably be expected to have some probability of influencing the rate or degree of habituation. This aspect of the review was car ried out with reference to three subgroups of the 34 studies reporting data on sex differences: (1) Group $M$-research finding male infants' habituation performance to be better than females' (as indexed by rate of response decrement and/or degree of discriminative response recovery), (2) Group F-studies showing females to display better habituation than males using the same criteria, and (3) Group ND-investigations finding no sex differences in habituation performance.

The procedural variables examined can be classified by the type of measurement permitted. Those variables which allowed only nominal measurement were: (1) infant held by adult vs. not 
held, (2) infant in reclining vs. upright position, (3) corneal reflection criterion for fixation vs. other fixation judgment criteria, (4) male vs. female observer(s), (5) fixed vs. infant-controlled trial length, ${ }^{2}$ (6) fixed number of habituation trials vs. training to a performance criterion, (7) achromatic vs. chromatic stimuli, (8) two- vs. three-dimensional (object) stimuli, (9) artificial or geometric vs. natural or realistic stimuli, (10) visual vs. auditory habituation stimulus, (11) visual fixation vs. other dependent measures (e.g., cardiac responses).

The other class of variables examined could be quantitatively measured. They were: (1) year of publication, (2) sample age (the mean or median age of the sample after subject loss), (3) distance of the stimulus from the infant (approximate distance between the stimulus and the infants's eyes, ears, or head), (4) actual size of the habituation stimulus, (5) number of stimuli, (6) intertrial interval (the number of seconds between presentations of the habituation stimulus, ${ }^{3}$ (7) trial length, (8) number of habituation training trials, ${ }^{5}$ (9) total number of trials (habituation training trials plus any additional trials for warm-up, presentation of interfering stimulation, and/or tests for discrimination or generalization), (10) habituation stimulus exposure time (the number of habituation trials $x$ trial length), (11) total stimulus exposure time (trial length $X$ total number of trials as defined in Item 9 above).

\section{Nominal Variables}

\section{RESULTS OF THE SURVEY}

Three questions were asked with respect to each nominal variable. First, does Group $M$ differ from Group F? Second, do studies finding sex differences in either direction (Group SD) differ from those in Group ND? Third, do Groups $M$ and F individually differ from the "baseline" provided by Group ND? To address these questions, Fisher exact tests were applied to comparisons of Groups M vs. F, SD vs. ND, M vs. ND, and F vs. ND for each of the nominal variables dichotomized in the manner indicated previously. All resulting p values were $\geqslant .24$.

\section{Quantitative Variables}

A series of Mann-Whitney $U$ tests comparing Groups $M$ and $F$ produced no significant differences on any quantitative variable (all ps $\geqslant .28$ ). (These and all subsequent $p$ values are two-tailed).

Prior to the comparisons of Groups SD and ND, the possible contribution to these comparisons of a subgroup of four ND studies of auditory habituation was examined (Bartoshuk, 1962b; Berg, 1972, 1974; Keen, 1964). Since these four investigations appeared to take on anomalous values for many of the quantitative variables, they were compared to the remaining ND experiments, all of which dealt with visual habituation, on each of the quantitative variables. The subgroups, ND-visual and NDauditory, differed with respect to intertrial interval $[U(21,4)=$ $12.5, \mathrm{p}<.05$, means of 9.21 and $34.90 \mathrm{sec}$, respectively ], trial length $[U(19,4)=6, p<.01$, means of 30.53 and $6.75 \mathrm{sec}$, habituation stimulus exposure time $[U(19,4)=11, p<.05$, means of 250.16 and $70.00 \mathrm{sec}$, and total stimulus exposure time $[\mathrm{U}(19,4)=12.5, \mathrm{p}<.05$, means of 476.13 and 125.00$]$. In addition, two other comparisons achieved marginal significance: number of stimuli presented $[\mathrm{U}(23,4)=19, \mathrm{p}<.07$, means of 4.06 and 1.75$]$ and year of publication $[U(23,4)=18.5, p<.07$, 1973.5 and 1968.0]. In view of these outcomes, and since all SD studies employed visual stimuli, the four ND studies of auditory habituation were excluded from the comparisons of Groups SD and ND on the six variables listed above.

With this restriction applied, Groups SD and ND were compared on all of the quantitative variables. Marginally significant differences were found for year of publication $[\mathrm{U}(7,23)=\mathbf{4 6 . 5}$, $\mathrm{p}<.10$, means of 1971.1 and 1973.5, respectively] and intertrial interval $[\mathrm{U}(6,21)=32, \mathrm{p}<.07$, means of 3.33 and $9.21 \mathrm{sec}]$.

The final series of comparisons between Groups $M$ vs. ND and $F$ vs. ND was also carried out with the restriction regarding studies of auditory habituation applied as above. There was one significant outcome: Groups $M$ vs. ND differed for intertrial interval $[U(3,21)=5, p<.05$, means of 1.33 and $9.21 \mathrm{sec}$,
Table 1

Mean Values for the Three Classes of Studies on Three Temporal Procedural Variables

\begin{tabular}{lcrr}
\hline \multicolumn{1}{c}{ Variables } & \multicolumn{3}{c}{ Groups of Studies } \\
\hline Intertrial Interval Length (sec) & 1.33 & ND & \multicolumn{1}{c}{ F } \\
Trial Length (sec) & 15.00 & $\mathbf{9 0 . 2 1}$ & $\mathbf{3 0 . 3 3}$ \\
Number of Habituation Trials & 11.50 & $\mathbf{9 . 0 5}$ & $\mathbf{2 9 . 6 7}$ \\
\hline
\end{tabular}

respectively]. Also, there were two marginally significant comparisons involving Groups $M$ and ND: trial length $[U(3,19)=$ $10.5, \mathrm{p}<.09$, means of 15.00 and $30.53 \mathrm{sec}$ ] and number of habituation trials $[\mathrm{U}(4,27)=23, \mathrm{p}<.07$, means of 11.50 and 9.05]. Table 1 shows the means of Groups $M, F$, and ND for these three variables.

To summarize, the chief findings of the survey of nominal and quantitative variables are: (1) studies finding sex differences were likely to have earlier publication dates than those not finding sex differences, and (2) compared to studies showing no sex differences, those finding superior habituation performance by male infants had shorter intertrial intervals and tended to have shorter trial lengths and a greater number of habituation trials.

\section{DISCUSSION}

Let us first address the indication that studies with a relatively large number of relatively short, rapidly paced stimulus exposures favor superior habituation performance by males, while studies incorporating the obverse of these values are associated with either no sex differences or with superior habituation performance by females. If we assume that short, rapidly paced stimulus exposures favor subjects who habituate rapidly (i.e., who rapidly complete their processing of the stimulus input), then the obtained pattern of results suggests that male infants habituate more rapidly than females. Under this view, the female infants in Group $M$ research were less likely than males to have completed their cognitive "model" of the stimulus (Sokolov, 1963) by the end of any given number of habituation trials. In contrast, the longer and slower paced stimulus exposures that characterized Group ND research allowed both male and female infants to complete their stimulus models. The fact that studies with longer and slower paced stimulus exposures also led on occasion to superior habituation performance by females can be accounted for by the assumption that on those occasions the faster male habituators, who could be expected to have habituated relatively early in the training series, became restive or "fussy" and were eliminated from the experiment. That is, those studies finding superior performance by females may have a male sample biased toward slower habituators.

The hypothesis that male infants habituate faster than females is made only with reference to performance measures (e.g., asymptotic fixation values), and thus leaves open the nature of the underlying process. Hence, faster habituation by males could mean either that males have a higher rate of processing the stimulus information than females or that they process the stimulus input in less detail or less completely than females.

The foregoing analysis enables a coherent account of the obtained pattern of data. First, there is the fact that none of the studies showing male infants superior to female infants produced conclusive evidence of habituation in the female subjects (Cohen et al., 1975, 1971; Cornell \& Strauss, 1973; Pancratz \& Cohen, 1970). This outcome is consistent with the suggestion that the distribution of stimulus exposure in these studies did not enable the females to construct a model of the habituation stimulus by the end of the habituation trials.

Second, two of the studies demonstrating better performance by female infants (Caron \& Caron, 1969; Friedman et al., 1974) did obtain clear evidence of habituation in males, but the males in those studies habituated more slowly and discriminated a novel stimulus more poorly than females, respectively. If procedures resulting in better habituation performance by females do tend to selectively eliminate faster male habituators, as suggested in the present analysis, it would be expected that the final sample 
of males would show a slower rate of habituation or poorer discrimination performance than females, rather than simply failing to habituate.

Finally, the proposed hypothesis also accounts for the marginally significant difference between Groups SD and ND in year of publication (means of 1971.1 and 1973.5, respectively). Following the introduction in 1972 of infant-controlled trial length procedures and of habituation performance criteria, as opposed to a fixed number of training trials, each of a set length (Friedman, 1972; Horowitz et al., 1972), the likelihood of obtaining sex differences has dropped markedly. Forty-four percent of the research analyzing for sex differences published prior to 1972 obtained sex differences in performance; since that date, only $14 \%$ have produced data influenced by sex. By allowing infants greater latitude in determining the degree and rate of stimulus availability, the new testing procedures have effectively circumvented the variables that the present survey suggests are related to findings of sex differences: intertrial interval, trial length, and number of habituation training trials.

The present review has uncovered intriguing evidence of an important sex difference in infant habituation performance. Although the evidence must be regarded as suggestive rather than firm, it seems sufficient to warrant further investigation of the hypothesized sex difference. A major barrier to clear assessment of the hypothesis is the frequent failure of investigators to report analyses for sex difference in performance. An important related consideration is that, due to the increasing popularity of the "infant-controlled" procedures, investigators are moving away from the very procedures that appear to be more clearly associated with the detection of sex differences in habituation. Therefore, it is important that the present sex difference findings, and the parameters associated with sex differences in performance, be immediately called to the attention of researchers in this area. Until direct tests of the hypothesized sex differences are available, investigators should, at the least, give greater attention to the analysis and reporting of possible sex differences in infant habituation performance.

\section{REFERENCE NOTES}

1. Ames, E. W. Stimulus complexity and age of infants as determinants of the rate of habituation of visual fixation. Paper presented at meetings of the Western Psychological Association, Long Beach, California, April 1966.

2. Cohen, L. B. Alternative measures of infant attention. Paper presented at the Society for Research in Child Development Symposium on Determinants of Attention in Infants, Santa Monica, March 1969.

3. Cohen, L. B. Concept acquisition in the human infant. Paper presented at the Society for Research in Child Development meeting, New Orleans, Louisiana, 1977.

4. Hunter, M. A., \& Ames, E. W. Visual habituation and preference for novelty. Paper presented at the meetings of the Society for Research in Child Development, Denver, Colorado, April 1975.

5. Miller, D. J., Adams, K. S., \& Ryan, E. B. Serial habituation in a retroactive interference paradigm. Unpublished manuscript, 1976.

6. Miller, D. J., Deslauriers, R. J., \& Farrow, B. J. Absence of sex effects in serial habituation. Unpublished manuscript, 1975.

\section{REFERENCES}

Adkinson, C. D., \& Berg, W. K. Cardiac deceleration in newborns: Habituation, dishabituation, and offset responses. Journal of Experimental Child Psychology, 1976, 21, 46-60.

Allen, T. W., Walker, K., Symonds, L., \& Marcell, M. Intrasensory and intersensory perception of temporal sequences during infancy. Developmental Psychology, 1977, 13, 225-229.

Appel, M. A., \& Campos, J. J. Binocular disparity as a discriminable stimulus parameier for young infants. Journal of Experimental Child Psychology, 1977, 23, 47-56.

BARToshuK, A. K. Human neonatal cardiac acceleration to sound: Habituation and dishabituation. Perceptual and Motor Skills, $1962,5,15-27$. (a)
Bartoshuk, A. K. Response decrement with repeated elicitation of human neonatal cardiac acceleration to sound. Journal of Comparative and Physiological Psychology, 1962, 55, 9-13. (b)

BERG, W. K. Habituation and dishabituation of cardiac responses in 4-month-old alert infants. Journal of Experimental Child Psychology, 1972, 14, 92-107.

BERG, W. K. Cardiac orienting responses of 6- and 16-week-old infants. Journal of Experimental Child Psychology, 1974, 17, 303-312.

Bornstein, M. H. Infants' recognition memory for hue. Developmental Psychology, 1976, 12, 185-191.

BrIDGER, W. H. Sensory habituation and discrimination in the human neonate. American Journal of Psychiatry, 1961, 117, 991-996.

Bronshtein, A. I., \& Petrova, E. P.[The auditory analyzer in infants.] From Issledovanie zvukovogo analizatora novorozhdennykh i detei rannego grudnogo vozrasta (An investigation of the auditory analyzer in neonates and young infants). Zh. Vyssh. Nerv. Deiatel. 1952, 2, 333-343.

BRown, C. J. The effects of preference for visual complexity on habituation of visual fixation in infants. Child Development, 1974 , 45, 1166-1169.

Caron, R. F., \& Caron, A. J. The effects of repeated exposure and stimulus complexity on visual fixation in infants. Psychonomic Science, 1968, 10, 207-208.

Caron, R. F., \& Caron, A. J. Degree of stimulus complexity and habituation of visual fixation in infants. Psychonomic Science, 1969, 14, 78-79.

Caron, A. J., Caron, R. F., Caldwell, R. C., \& Weiss, S. J. Infant perception of the structural properties of the face. Developmental Psychology, 1973, 9, 385-399.

Clifton, R. K., Graham, F. K., \& Hatton, H. M. Newborn heart-rate response and response habituation as a function of stimulus duration. Journal of Experimental Child Psychology, 1968, 6, 265-278.

Cohen, L. B. A two process model of infant visual attention. Merrill-Palmer Quarterly of Behavior and Development, 1973, 19, 157-180.

Cohen, L. B., DeLoache, J. S., \& Pearl, R. A. An examination of interference effects in infants' memory for faces. Child Development, 1977, 48, 88-96.

Cohen, L. B., DeLoache, J. S., \& Rissman, M. W. The effect of stimulus complexity on infant visual attention and habituation. Child Development, 1975, 46, 611-617.

Cohen, L. B., \& Gelber, E. R. Infant visual memory. In L. Cohen \& P. Salapatek (Eds.), Infant perception: From sensation to $c o g$ nition (Vol. 1). New York: Academic Press, 1975.

Cohen, L. B., Gelber, E. R., \& LAzAR, M. A. Infant habituation and generalization to differing degrees of stimulus novelty. Journal of Experimental Child Psychology, 1971, 11, 379-389.

Collard, R. R., \& RYdberg, J. E. Generalization of habituation to properties of objects in human infants. Proceedings of the 80 th Annual Convention of the American Psychological Association, 1972, 7, 81-82.

Cornell, E. H., \& Strauss, M. S. Infants' responsiveness to compounds of habituated visual stimuli. Developmental Psychology, 1973, 9. 73-78.

DELOACHE, J. S. Rate of habituation and visual memory in infants. Child Development, 1976, 47, 145-154.

Dirks, J., \& GiBson, E. Infants' perception of similarity between live people and their photographs. Child Development, 1977, 48, 124-130.

Eisenberg, R. B., Coursin, D. B., \& Rupp, N. R. Habituation to an acoustic pattern as an index of differences among human neonates. Journal of Auditory Research, 1966, 6, 239-248.

ENGEN, T., \& LipsiTT, L. P. Decrement and recovery of responses to olfactory stimuli in the human neonate. Journal of Comparative and Physiological Psychology, 1965, 12, 312-316.

Engen, T., LipsitT, L. P., \& KAYE, H. Olfactory responses and adaptation in the human neonate. Journal of Comparative and Physiological Psychology, 1963, 56, 73-77.

FANTZ, R. L. Visual experience in infants: Decreased attention 
to familiar patterns relative to novel ones. Science, 1964 , 146, 668-670.

Friedman, S. Habituation and recovery of visual response in the alert human newborn. Journal of Experimental Child Psychology, 1972, 13, 339-349.

Friedman, S., Bruno, L. A., \& Vietze, P. Newborn habituation to visual stimuli: A sex difference in novelty detection. Journal of Experimental Child Psvchology, 1974, 18, 242-251.

Friedman, S., \& Carpenter, G. C. Visual response decrement as a function of age of human newborn. Child Development, 1971, 42, 1967-1973.

Friedman, S., Carpenter, G. C., \& Nagy, A. N. Decrement and recovery of response to visual stimuli in the newborn human. Proceedings of the 78th Annual Convention of the American Psychological Association, 1970, 5, 273-274.

Friedman, S., Nagy, A. N., \& Carpenter, G. C. Newborn attention: Differential response decrement to visual stimuli. Journal of Experimental Child Psychology, 1970, 10, 44-51.

Friedman, S., Schlossnagle, S., Ramsey, B., \& Rogers, P. P. Habituation in early infancy: Mothers as "experimenters." Proceedings of the 81st Annual Convention of the American Psychological Association, 1973, 8, 67-68.

Graham, F. K., Clifton, R. K., \& Hatton, H. M. Habituation of heart rate response to repeated auditory stimulation during the first five days of life. Child Development, 1968, 39, 35-52.

Greenberg, D. J., O'Donnell, W. J., \& Crawford, D. Complexity levels, habituation, and individual differences in early infancy. Child Development, 1973, 44, 569-574.

Horowitz, A. B. Habituation and memory: Infant cardiac responses to familiar and discrepant stimuli. Child Development, 1972, 43, 43-53.

Horowitz, F. D., Paden, L., Bhana, K., \& Self, P. An "infant control" procedure for studying infant visual fixations. Developmental Psychology, 1972, 7, 90.

Hutt, C., von Bernuth, H., Lenard, H. G., Hutt, S. J., \& Prechts, H. F. R. Habituation in relation to state in the human neonate. Nature, 1968, 220, 618-620.

JoHNSON, D., \& BRODY, N. Visual habituation, sensorimotor development, and tempo of play in one-year-old infants. Child Development, 1977, 48, 315-319.

KagAN, J., \& LewIS, M. Studies of attention in the human infant. Merrill-Palmer Quarterly of Behavior and Development, 1965, 11, 95-127.

KEEN, R. E. Effects of auditory stimuli on sucking behavior in the human neonate. Journal of Experimental Child Psychology, 1964, 1, 348-354.

Keen, R. E., Chase, H. H., \& Graham, F. K. Twenty-four hour retention by neonates of an habituated heart response. Psychonomic Science, 1965, 2, 265-266.

Leavitt, L. A., Brown, J. W., Morse, P. A., \& Graham, F. K. Cardiac orienting and auditory discrimination in 6-week-old infants. Developmental Psychology, 1976, 12, 514-523.

MaccoBy, E. E., \& JACKLIN, C. N. The psychology of sex differences. Stanford, Calif: Stanford University Press, 1974.

MarTin, R. M. Effects of familiar and complex stimuli on infant attention. Developmental Psychology, 1975, 11, 178-185.

MCCALL, R. B. Encoding and retrieval of perceptual memories after long-term familiarization and the infant's response to discrepancy. Developmental Psychology, 1973, 9, 310-318.

McCall, R. B., Hogarty, P. S., Hamilton, J. S., \& Vincent, J. H. Habituation rate and the infant's response to visual discrepancies. Child Development, 1973, 44, 280-287.

MCCALL, R. B., \& KAGAN, J. Individual differences in the infant's distribution of attention to stimulus discrepancy. Developmental Psychology, 1970, 2, 90-98.

McCall, R. B., Kennedy, C. B., \& Dodds, C. The interfering effect of distracting stimuli on the infant's memory. Child Development, 1977, 48, 79-87.

McCall, R. B., \& Melson, W. H. Attention in infants as a function of magnitude of discrepancy and habituation rate. Psychonomic Science, 1969, 17, 317-319.
McCall, R. B., \& Melson, W. H. Amount of short-term familiarization and the response to auditory discrepancies. Child Development, 1970, 41, 861-869.

McGuRK, H. The role of object orientation in infant perception. Journal of Experimental Child Psychology, 1970, 9, 363-373.

MCGURK, H. Infant discrimination of orientation. Journal of Experimental Child Psychology, 1972, 14, 151-164.

Melson, W. H., \& McCALL, R. B. Attentional responses of fivemonth girls to discrepant auditory stimuli. Child Development, 1970, 41, 1159-1171.

MeYers, W. J., \& Cantor, G. N. Infants' observing and heart period responses related to novelty of visual stimuli. Psychonomic Science, 1966, 5, 239-240.

Miller, D. J. Visual habituation in the human infant. Child Development, 1972, 43, 481-493.

Miller, D. J., Ryan, E. B., Sinnott, J. P., \& Wilson, M. A. Serial habituation in two-, three-, and four-month-old infants. Child Development, 1976, 47, 341-349.

Miller, D. J., Turnure, C., \& Cohen, L. B. Habituation of visual fixations in human infants in a retroactive inhibition paradigm. Proceedings of the 78th Annual Convention of the American Psychological Association, 1970, 5, 277-278.

Moreau, T., BIRCH, H. G., \& TURKewITZ, G. Base of habituation to repeated auditory and somesthetic stimulation in the human newborn. Journal of Experimental Child Psychology, 1970, 9, 193-207.

Morse, P. A. The discrimination of speech and nonspeech stimuli in early infancy. Journal of Experimental Child Psychology, 1972, 14, 477-492.

Pancratz, C. N., \& Cohen, L. B. Recovery of habituation in infants. Journal of Experimental Child Psychology, 1970, 9, 208-216.

PARRY, M. H. Responses to novelty in familiar and unfamiliar settings. Child Development, 1972, 43, 233-237.

RufF, H. A. The function of shifting fixations in the visual perception of infants. Child Development, 1975, 46, 857-865.

SaAman, G., Ames, E. W., \& Moffett, A. Response to novelty as an indicator of visual discrimination in the human infant. Journal of Experimental Child Psychology, 1964, 1, 189-198.

Schaffer, H. R., Greenwood, A., \& ParRY, M. H. The onset of wariness. Child Development, 1972, 43, 165-175.

Schaffer, H. R., \& PARRY, M. H. Perceptual-motor behaviour in infancy as a function of age and stimulus familiarity. British Journal of Psychology, 1969, 60, 1-9.

Soxolov, E. N. Perception and the conditioned reflex. Oxford: Pergamon Press, 1963.

Steele, D., \& Pederson, D. R. Stimulus variables which affect the concordance of visual and manipulative exploration in sixmonth-old infants. Child Development, 1977, 48, 104-111.

Wetherford, M. J., \& Cohen, L. B. Developmental changes in infant visual preferences for novelty and familiarity. Child Development, 1973, 44, 416-424.

Young-Browne, G., Rosenfeld, H. M., \& Horowitz, F. D. Infant discrimination of facial expressions. Child Development, 1977, 48, 555-562.

\section{NOTES}

1. Some of these studies produced significant sex differences in the absolute amount of visual fixation time (Caron et al., 1973; Cohen et al., 1977; DeLoache, 1976; Kagan \& Lewis, 1965). Others found sex to be a factor in significant higher order interactions, usually of an uninterpretable nature (Berg, 1972; Friedman \& Carpenter, 1971; Friedman et al., 1970; Keen, 1964; McCall et al., 1973; McCall \& Kagan, 1970).

2. Infant-controlled refers to procedures originated by Cohen (1973) and Horowitz, Paden, Bhana, and Self (1972).

3. The intertrial interval factor could not be scored in studies using Cohen's (1973) infant-control procedure.

4. Studies using infant-controlled trial lengths were included in the analysis only if they enabled determination of a mean trial length figure.

5. Studies using habituation criteria were included if they permitted determination of an average number of trials to criterion.

(Received for publication July 2, 1978.) 